\title{
Corrigendum: Multivariate Analyses of Balance Test Performance, Vestibular Thresholds, and Age
}

\author{
Faisal Karmali ${ }^{1,2 *}$, María Carolina Bermúdez Rey ${ }^{1,2}$, Torin K. Clark ${ }^{1,2,3}$, Wei Wang ${ }^{2,4}$ and \\ Daniel M. Merfeld ${ }^{1,2}$
}

\begin{abstract}
1 Jenks Vestibular Physiology Laboratory, Mass Eye and Ear Infirmary, Boston, MA, United States, ${ }^{2}$ Otolaryngology, Harvard Medical School, Harvard University, Boston, MA, United States, ${ }^{3}$ Smead Aerospace Engineering Sciences, University of Colorado, Boulder, CO, United States, ${ }^{4}$ Division of Sleep Medicine, Brigham and Women's Hospital, Boston, MA, United States
\end{abstract}

Keywords: vestibular, balance, perception, thresholds, aging, multivariate

\section{A Corrigendum on}

\section{OPEN ACCESS}

Edited by:

Barry M. Seemungal, Imperial College London, United Kingdom

Reviewed by: Amir Kheradmand, Johns Hopkins University,

United States

Qadeer Arshad,

University of Leicester, United Kingdom

*Correspondence: Faisal Karmali faisal_karmali@yahoo.com

Specialty section:

This article was submitted to Neuro-Otology,

a section of the journal

Frontiers in Neurology

Received: 28 April 2020 Accepted: 05 November 2020 Published: 26 November 2020

Citation:

Karmali F, Bermúdez Rey MC Clark TK, Wang W and Merfeld DM (2020) Corrigendum: Multivariate Analyses of Balance Test Performance, Vestibular Thresholds, and Age. Front. Neurol. 11:556797.

doi: 10.3389/fneur.2020.556797
Multivariate Analyses of Balance Test Performance, Vestibular Thresholds, and Age by Karmali, F., Bermúdez Rey, M. C., Clark, T. K., Wang, W., and Merfeld, D. M. (2017). Front. Neurol. 8:578. doi: 10.3389/fneur.2017.00578

In the original article, there was an error. We realized there was a typographical error in a sentence of the Results section that describes a previous paper, such that the " $y$-" and "z-" were reversed.

A correction has been made to Results, The Relationship between Vestibular Thresholds and Condition 4 of the Modified Romberg Foam Test, Paragraph 1. The corrected paragraph reads:

Our previous study (1) examined the basic relationship between failing condition 4 of the Modified Romberg test and vestibular thresholds. However, those analyses only looked at the relationship between each individual threshold and the chance of failing the test, without performing multivariate analyses. Specifically, we performed single-variable logistic regressions between failures and each age-adjusted threshold. There were statistically significant correlations with roll $0.2 \mathrm{~Hz}(p=0.003)$ and roll $1 \mathrm{~Hz}(p=0.02)$ thresholds, a suggestion of possible correlation with yaw $1 \mathrm{~Hz}(p=0.09)$ and z-translation $1 \mathrm{~Hz}(p=0.09)$ thresholds, and a non-significant correlation for $y$-translation $(p=0.50)$ thresholds. Given that thresholds may be correlated with each other, a weakness of this analysis was that it did not determine if the covariation between thresholds described above could have resulted in an artifact of some thresholds being correlated with the chance of failing condition 4 .

The authors apologize for this error and state that it does not change the scientific conclusions of the article in any way. The original article has been updated.

\section{REFERENCES}

1. Bermúdez Rey M, Clark T, Wang W, Leeder T, Bian Y, Merfeld D. Vestibular perceptual thresholds increase above the age of 40. Front Neurol. (2016) 7(162):162. doi: 10.3389/fneur.2016.00162

Copyright $\odot 2020$ Karmali, Bermúdez Rey, Clark, Wang and Merfeld. This is an open-access article distributed under the terms of the Creative Commons Attribution License (CC BY). The use, distribution or reproduction in other forums is permitted, provided the original author(s) and the copyright owner(s) are credited and that the original publication in this journal is cited, in accordance with accepted academic practice. No use, distribution or reproduction is permitted which does not comply with these terms. 